ARTICLE

\title{
Construction of $\mathrm{Pd}-\mathrm{Zn}$ dual sites to enhance the performance for ethanol electro-oxidation reaction
}

Yajun Qiu', Jian Zhang ${ }^{2 凶}{ }^{\star}$, Jing Jin ${ }^{3}$, Jiaqiang Sun ${ }^{4}$, Haolin Tang ${ }^{5}$, Qingqing Chen ${ }^{6}$, Zedong Zhang ${ }^{1}$ Wenming Sun (1) ${ }^{7 凶}$, Ge Meng ${ }^{2}$, Qi Xu1 , Youqi Zhu ${ }^{8}$, Aijuan $\mathrm{Han}^{3}$, Lin Gu (1) ${ }^{9}$, Dingsheng Wang ${ }^{1 凶} \&$ Yadong Li (iD ${ }^{1}$

Rational design and synthesis of superior electrocatalysts for ethanol oxidation is crucial to practical applications of direct ethanol fuel cells. Here, we report that the construction of Pd$\mathrm{Zn}$ dual sites with well exposure and uniformity can significantly improve the efficiency of ethanol electro-oxidation. Through synthetic method control, $\mathrm{Pd}-\mathrm{Zn}$ dual sites on intermetallic PdZn nanoparticles, $\mathrm{Pd}-\mathrm{Pd}$ sites on $\mathrm{Pd}$ nanoparticles and individual $\mathrm{Pd}$ sites are respectively obtained on the same $\mathrm{N}$-doped carbon coated $\mathrm{ZnO}$ support. Compared with $\mathrm{Pd}-$ $\mathrm{Pd}$ sites and individual $\mathrm{Pd}$ sites, $\mathrm{Pd}-\mathrm{Zn}$ dual sites display much higher activity for ethanol electro-oxidation, exceeding that of commercial Pd/C by a factor of $\sim 24$. Further computational studies disclose that $\mathrm{Pd}-\mathrm{Zn}$ dual sites promote the adsorption of ethanol and hydroxide ion to optimize the electro-oxidation pathway with dramatically reduced energy barriers, leading to the superior activity. This work provides valuable clues for developing highperformance ethanol electro-oxidation catalysts for fuel cells.

\footnotetext{
${ }^{1}$ Department of Chemistry, Tsinghua University, Beijing, China. ${ }^{2}$ College of Chemistry and Materials Engineering, Wenzhou University, Wenzhou, Zhejiang, China. ${ }^{3}$ State Key Laboratory of Chemical Resource Engineering, Beijing University of Chemical Technology, Beijing, China. ${ }^{4}$ State Key Laboratory of Coal Conversion, Institute of Coal Chemistry, Chinese Academy of Sciences, Taiyuan, Shanxi, China. ${ }^{5}$ State Key Laboratory of Advanced Technology for Materials Synthesis and Processing, Wuhan University of Technology, Wuhan, China. ${ }^{6}$ Key Laboratory of Functional Molecular Solids, Ministry of Education, College of Chemistry and Materials Science, Anhui Normal University, Wuhu, Anhui, China. ${ }^{7}$ College of Science, China Agricultural University, Beijing, China.

${ }^{8}$ Research Center of Materials Science, Beijing Institute of Technology, Beijing, China. ${ }^{9}$ Institute of Physics, Chinese Academy of Sciences, Beijing, China.

凶email: zhangjian1209@outlook.com; swm@cau.edu.cn; wangdingsheng@mail.tsinghua.edu.cn
} 
D irect ethanol fuel cells (DEFCs) have attractive application prospect in the fields of power generation, fixation, and transformation for their good agreement with the urgent demand of current energy and environment ${ }^{1-15}$. The development of highly active and low-cost electrocatalysts for the ethanol oxidation reaction (EOR) lays at the heart of DEFCs ${ }^{16-25}$. Downsizing of metal nanoparticles into individual metal sites is commonly regarded as an efficient approach to enhance the performance and cost-effectiveness of electrocatalysts, but may be improper for specific reactions catalyzed by multiple sites or peculiar active centers ${ }^{26-31}$. For now, alloying of Pd with base metals (M) like $\mathrm{Zn}, \mathrm{Ni}, \mathrm{Sn}, \mathrm{Co}, \mathrm{Cu}, \mathrm{Ge}$, etc. to construct Pd-M dual sites, which are more active for EOR than pure Pd sites ${ }^{32-43}$. The superior activity of such dual sites is generally considered to arise from base metals tuning the electronic property of $\mathrm{Pd}$ or synergistically taking part in the reaction ${ }^{44,45}$. The ambiguous role of the dual sites is the major obstacle to creating promising electrocatalysts for $\mathrm{EOR}^{46-48}$. In addition, in order to increase the exposure and uniformity of dual sites for better performance, common solvothermal methods are utilized to synthesize smallsized intermetallic compounds but usually cause residual surfactants covering dual sites with insufficient EOR performance ${ }^{49-52}$. Hence, it is highly desirable to develop efficient means to establish exposed and uniform Pd-M dual sites for prominent EOR electrocatalysts, and clarify their true principle of promotion effect for the rational design of new catalysts.

Herein, we demonstrate an effective strategy to fabricate $\mathrm{Pd}-\mathrm{Zn}$ dual sites for efficient EOR with Pd-Pd sites and individual $\mathrm{Pd}$ sites as references for investigating the mechanism of promotion effect. Volatile $\mathrm{Zn}$ atoms from $\mathrm{ZnO}$ nanorods can bound $\mathrm{Pd}$ atoms on $\mathrm{N}$-doped carbon to form well exposed and uniform $\mathrm{Pd}-\mathrm{Zn}$ dual sites. The $\mathrm{Pd}-\mathrm{Zn}$ dual sites make the catalyst (PdZn/NC@ZnO) perform the much higher mass activity than the other two catalysts with $\mathrm{Pd}-\mathrm{Pd}$ sites $\left(\mathrm{Pd}_{\mathrm{n}} / \mathrm{NC@ZnO}\right)$ and individual $\mathrm{Pd}$ sites $\left(\mathrm{Pd}_{1} / \mathrm{NC} @ \mathrm{ZnO}\right)$, and even commercial $\mathrm{Pd} / \mathrm{C}$ by $\sim 24$ times. Further DFT calculations manifest that Pd-Zn dual sites are beneficial to adsorbing ethanol and hydroxide ion with lower reaction energy, tuning the reaction pathway of EOR with significant reduced energy barriers in contrast to $\mathrm{Pd}-\mathrm{Pd}$ and individual $\mathrm{Pd}$ sites, which accounts for the improved activity of PdZn/NC@ZnO.

\section{Results}

Synthesis and characterization of the catalysts. The fabrication of PdZn/NC@ZnO is realized by a polydopamine (PDA) confined and $\mathrm{Zn}$ vapor-assisted strategy (Fig. 1a). First, $\mathrm{ZnO}$ nanorods are pre-synthesized as the support via the reported method (Fig. $1 \mathrm{~b})^{53}$. Then, the support is coated with a regular layer of PDA $(\sim 10-20 \mathrm{~nm})$ as is observed by transmission electron microscopy (TEM) (Fig. 1c and Supplementary Fig. 1). Next, $\mathrm{Pd}(\mathrm{OH})_{2}$ is loaded on the PDA layer through slowly precipitating Pd precursors with alkali, which is confirmed by X-ray diffraction (XRD) and TEM detections showing no obvious nanoparticles (NPs) (Supplementary Fig. 2). Under high-temperature reduction with $\mathrm{H}_{2}$, the PDA layer transforms into $\mathrm{N}$-doped carbon (NC) to restrict the migration of $\mathrm{Pd}$ atoms, and the $\mathrm{Zn}$ vapor is generated from $\mathrm{ZnO}$ for bounding $\mathrm{Pd}$ atoms to form $\mathrm{Pd}-\mathrm{Zn}$ dual sites, finally leading to intermetallic PdZn NPs as evidenced by the scanning transmission electron microscopy (STEM) (Fig. 1d). The statistical distribution reveals the average particle size of such PdZn NPs being as small as $4.75 \pm 0.77 \mathrm{~nm}$ (the inset in Fig. $1 \mathrm{~d}$ and Supplementary Fig. 3). The size of PdZn NPs being small can be also reflected by the XRD detection which shows no PdZn signals except for neat $\mathrm{ZnO}$ peaks (Supplementary Fig. 4). After the $\mathrm{ZnO}$ being etched away, there are still PdZn NPs on the NC carrier in Supplementary Fig. 5a, and only graphitic carbon peaks are observed in the XRD patterns because of the PdZn NPs being too small (Supplementary Fig. 5c). When the loading of Pd precursor is increased five times, it can be seen that PdZn NPs become larger and exhibit featured intermetallic PdZn signals in the XRD patterns (Supplementary Fig. 5b, c), which suggests the nature of the PdZn NPs in PdZn/NC@ZnO being PdZn intermetallic compounds 54,55

In order to confirm the composition of PdZn NPs, energydispersive X-ray spectroscopy (EDS) line scanning measurement is first carried out (Fig. 1e). The profile displays that X-ray counts of $\mathrm{Pd}$ and $\mathrm{Zn}$ fluctuate in a similar manner, indicating the simultaneous presence of $\mathrm{Pd}$ and $\mathrm{Zn}$ atoms in the nanoparticle. Further atomic-resolution EDS elemental mapping analysis manifests that $\mathrm{Pd}$ and $\mathrm{Zn}$ homogeneously dispersed over the entire nanoparticle (Fig. If and Supplementary Fig. 6). The typical aberration-corrected high-angle annular dark-field scanning transmission electron microscope (AC HAADF-STEM) image of one nanoparticle exhibits clear bright dots, within which the heavier Pd atoms (bright) can be distinguished from $\mathrm{Zn}$ atoms (darker) (Fig. 1g). More importantly, the ordering of these bright dots accords with the atomic arrangement of (002) plane in the intermetallic $\mathrm{PdZn}(\mathrm{P} 4 / \mathrm{mmm})$ crystal structure, and the lattice spacing of 2.1 and $2.9 \AA$ also agree with inter-plane distances of (200) and (110) planes (Fig. 1g and Supplementary Fig. 7). Besides, the intermetallic PdZn (111) planes can be also observed on the nanoparticle by high-resolution transmission electron microscopy (HR-TEM) (Supplementary Fig. 8). These results testify the intermetallic nature of PdZn NPs with uniform Pd-Zn dual sites in PdZn/NC@ZnO. In contrast, when treated at low temperature $\left(400^{\circ} \mathrm{C}\right)$ to avoid the $\mathrm{Zn}$ vapor, only smaller Pd NPs $(2.75 \pm 0.66 \mathrm{~nm})$ with $\mathrm{Pd}-\mathrm{Pd}$ sites are formed in the catalyst $\left(\mathrm{Pd}_{\mathrm{n}} /\right.$ NC@ZnO) as deduced from STEM, TEM, and EDS line scanning tests (Fig. 1h, Supplementary Figs. 9-12). Moreover, individual $\mathrm{Pd}$ sites can be even obtained on the same support $\left(\mathrm{Pd}_{1} /\right.$ $\mathrm{NC@ZnO)} \mathrm{through} \mathrm{the} \mathrm{milder} \mathrm{synthetic} \mathrm{condition}\left(200^{\circ} \mathrm{C}\right)$, as determined by the solely bright dots assigned to isolated $\mathrm{Pd}$ atoms showed in the AC HAADF-STEM image (Fig. 1i and Supplementary Figs. 13-15). The smaller Pd NPs and individual Pd sites testify the PDA layer confining the aggregation of Pd atoms. The loading amount of $\mathrm{Pd}$ is $0.30,0.40$, and $0.35 \mathrm{wt} \%$ for $\mathrm{PdZn} /$

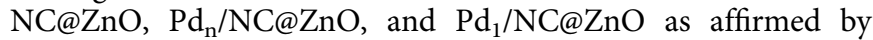
inductively coupled plasma optical emission spectrometry (ICPOES) measurements.

The different dispersion of $\mathrm{Pd}$ in three samples can be also verified by X-ray absorption spectrometry techniques (XAS) (Fig. 2a). Fourier transformed extended X-ray absorption fine structure (FT-EXAFS) spectra at Pd K-edge show that the first nearest-coordination peak of Pd in PdZn/NC@ZnO locates at the smaller $\mathrm{R}$ value of $2.2 \AA$ in comparison with that in Pd foil at $2.5 \AA$ from the Pd-Pd contribution (for corresponding EXAFS in k-space, see Supplementary Fig. 16). The fitting analysis elucidates that this first shell peak is contributed from $\mathrm{Pd}-\mathrm{Zn}$ $(\sim 2.6 \AA)$ and longer Pd-Pd $(\sim 2.8 \AA)$ bonds, coinciding with the atomic structure of intermetallic PdZn compound (Supplementary Fig. 17 and Supplementary Table 1). While for $\mathrm{Pd}_{\mathrm{n}} /$ $\mathrm{NC@ZnO}$ and $\mathrm{Pd}_{1} / \mathrm{NC@ZnO}$, there is the only one peak from shorter Pd-Pd bond (2.5 $\AA$ ) and Pd-N(C) bond (1.7 $\AA$ ) in their FT-EXAFS curves (Supplementary Fig. 17 and Supplementary Table 1). These results further demonstrate $\mathrm{Pd}$ species existing as $\mathrm{Pd}-\mathrm{Zn}$ dual sites, $\mathrm{Pd}-\mathrm{Pd}$, and individual $\mathrm{Pd}$ sites in three catalysts.

The electronic structure of three catalysts is next investigated through $\mathrm{Pd}$ K-edge X-ray absorption near edge structure (XANES) spectroscopy. The adsorption edge energy $\left(E_{0}\right)$ of $\mathrm{PdZn} / \mathrm{NC} @ \mathrm{ZnO}$ is higher than that of $\mathrm{Pd}$ foil and $\mathrm{Pd}_{\mathrm{n}} / \mathrm{NC} @ \mathrm{ZnO}$ 

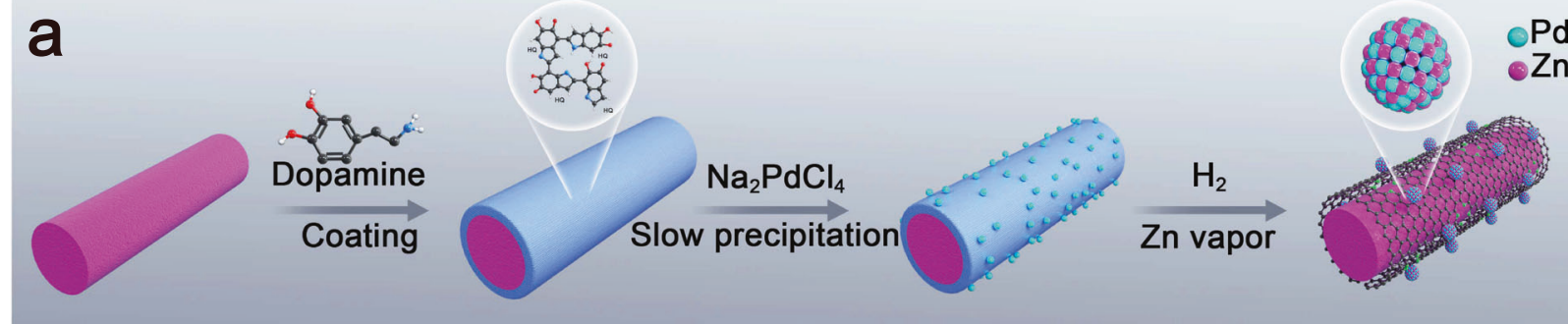

$\mathrm{ZnONRs}$

ZnO@PDA

$\mathrm{Pd}(\mathrm{OH})_{2} / \mathrm{ZnO} @ P D A$

$\mathrm{PdZn/NC@ZnO}$

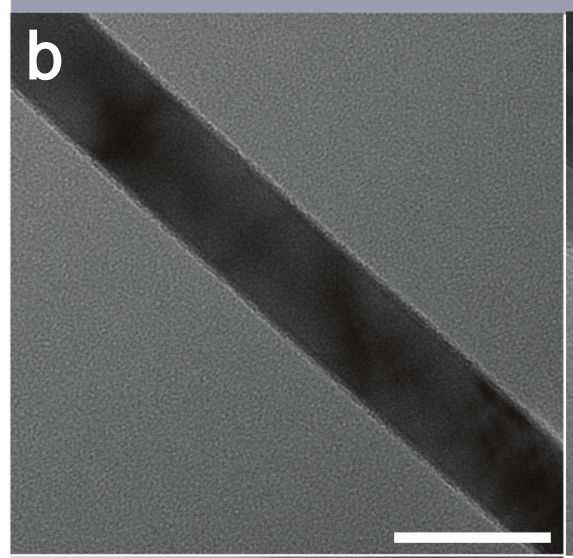

C
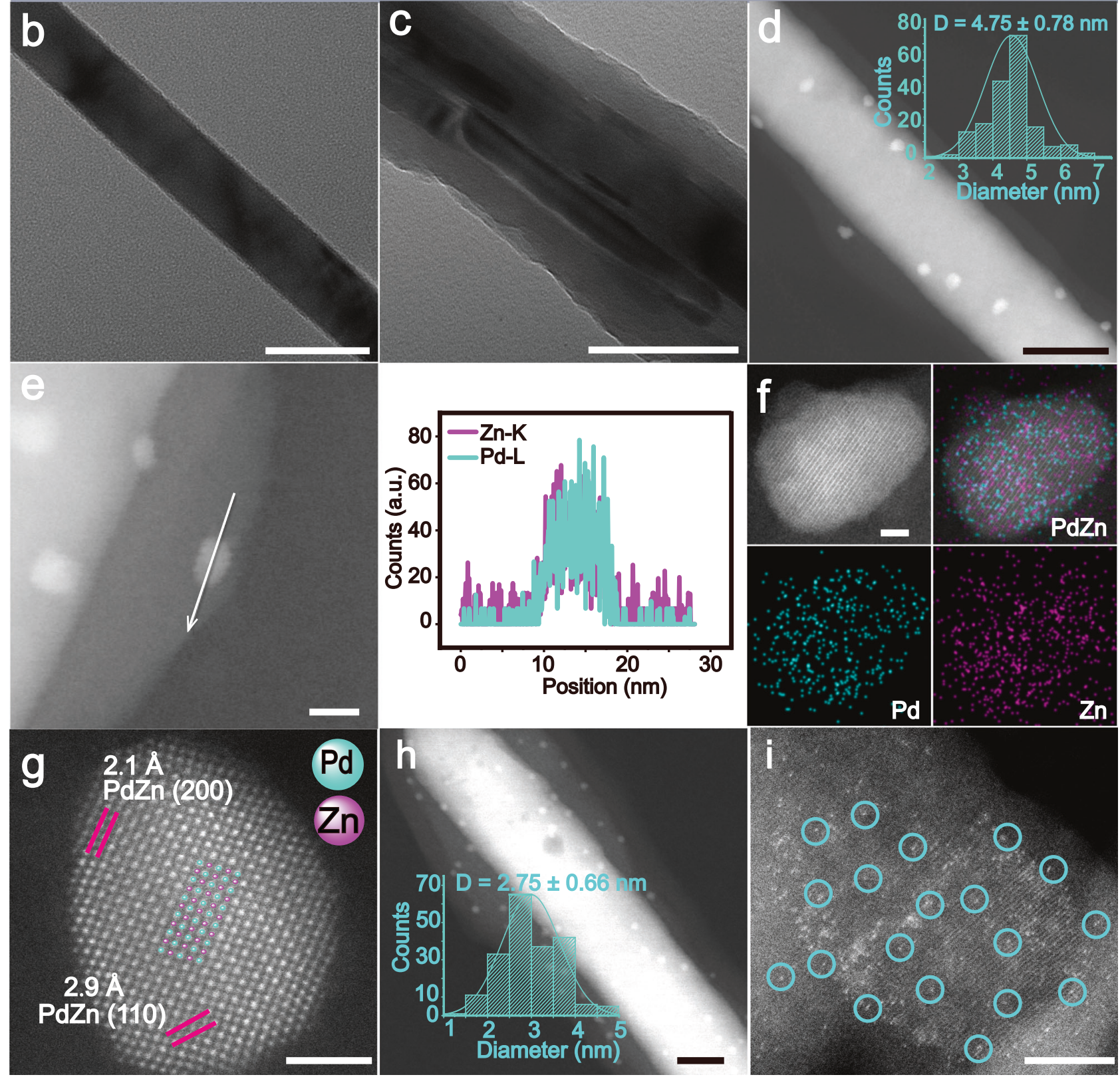

Fig. 1 Synthetic scheme and characterizations of synthesized catalysts. a Synthetic strategy of PdZn/NC@ZnO. b TEM image of ZnO nanorods. Scale bar, $50 \mathrm{~nm}$. c TEM image of ZnO@PDA. Scale bar, $100 \mathrm{~nm}$. d STEM image of PdZn/NC@ZnO, the inset is the size distribution histogram of PdZn nanoparticles in PdZn/NC@ZnO. Scale bar, 50 nm. e EDS line scanning profile across one PdZn nanoparticle in PdZn/NC@ZnO.The signals were collected from the Pd L edge and the Zn K-edge. Scale bar, $10 \mathrm{~nm}$. f AC HAADF-STEM image of one PdZn nanoparticle in PdZn/NC@ZnO. Scale bar, 2 nm. $\mathbf{g}$ AC HAADF-STEM elemental mappings of one PdZn nanoparticle in PdZn/NC@ZnO. Scale bar, $2 \mathrm{~nm}$. $\mathbf{h}$ STEM image of $P d_{n} / N C @ Z n O$, the inset is the size distribution histogram of Pd nanoparticles in Pd $/$ NC@ZnO. Scale bar, 20 nm. i AC HAADF-STEM image of Pd $/$ NC@ZnO. Scale bar, 5 nm. 

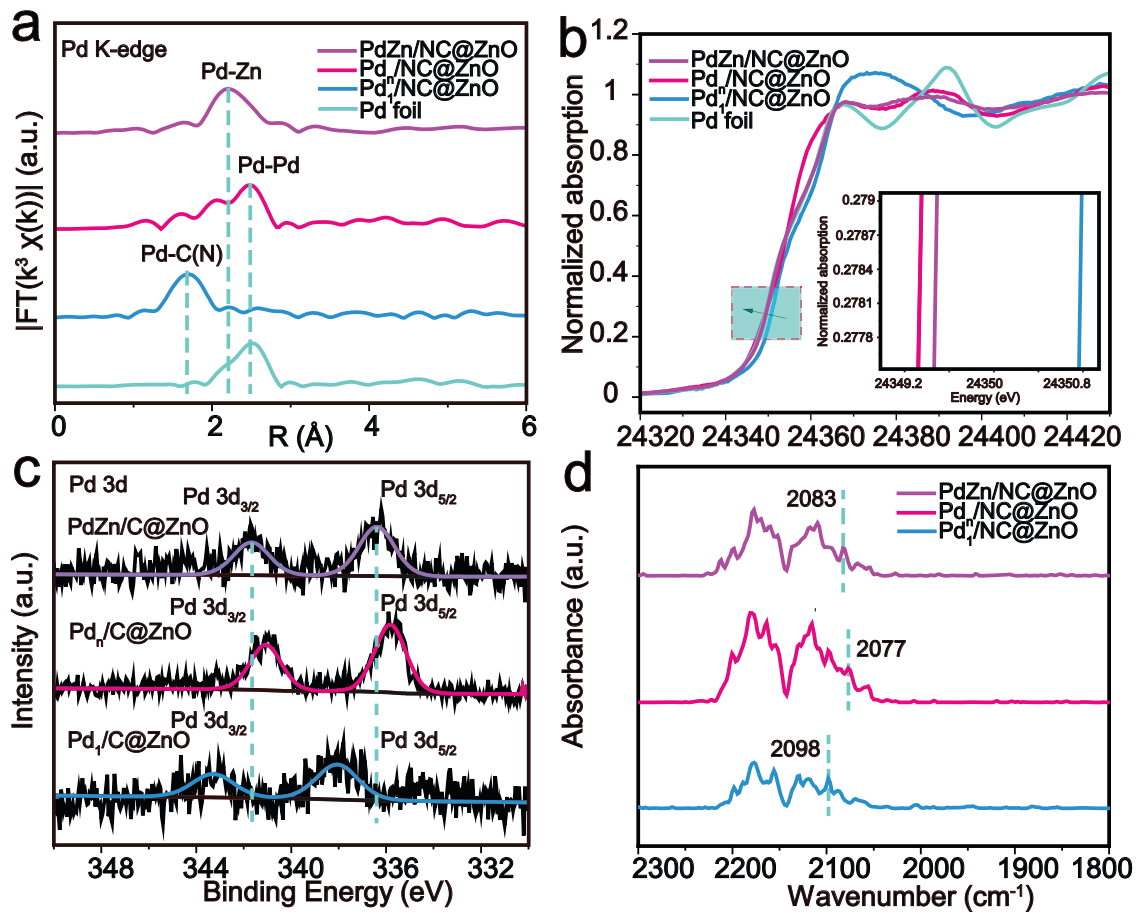

Fig. 2 X-ray absorption spectroscopy characterization of the catalysts. a FT-EXAFS spectra at the Pd k-edge of PdZn/NC@ZnO, Pdn $/ N C @ Z n O$, and Pd $/ 1$ NC@ZnO with Pd foil as the reference. b XANES spectra at the Pd k-edge of PdZn/NC@ZnO, Pdn $/ N C @ Z n O$, and Pd $/$ NC@ZnO with Pd foil as the reference. cXPS spectra in Pd 3d region of PdZn/NC@ZnO,Pdn/NC@ZnO, and Pd $/$ NC@ $@$ ZnO.d DRIFT spectra for PdZn/NC@ZnO,Pdn/NC@ZnO, and $\mathrm{Pd}_{1}$ /NC@ZnO.

but much lower than that of $\mathrm{Pd}_{1} / \mathrm{NC} @ \mathrm{ZnO}$ (Fig. 2b), indicating that the electron density of $\mathrm{Pd}$ decreases sightly for $\mathrm{PdZn} /$ $\mathrm{NC@ZnO} \mathrm{but} \mathrm{significantly} \mathrm{for} \mathrm{Pd}_{1} / \mathrm{NC} @ Z n O$ with respect to $\mathrm{Pd}_{\mathrm{n}} /$ NC@ZnO. This conclusion can be also drawn from X-ray photoelectron spectroscopy (XPS) and CO diffuse reflection infrared Fourier transform spectroscopy (CO-DRIFTS) studies. It can be evidenced from XPS spectra that $\mathrm{Pd} 3 d$ signal of $\mathrm{PdZn} /$ $\mathrm{NC@ZnO} \mathrm{locates} \mathrm{rightly} \mathrm{between} \mathrm{that} \mathrm{of} \mathrm{Pd}_{\mathrm{n}} / \mathrm{NC} @ \mathrm{ZnO}$ and $\mathrm{Pd}_{1} /$ $\mathrm{NC@ZnO,} \mathrm{revealing} \mathrm{the} \mathrm{moderate} \mathrm{electron} \mathrm{density} \mathrm{of} \mathrm{Pd}$ in PdZn/NC@ZnO (Fig. 2c). Moreover, CO-DRIFTS experiments disclose that $\mathrm{CO}$ stretching frequency has a blue shift from $2077 \mathrm{~cm}^{-1}$ for $\mathrm{Pd}_{\mathrm{n}} / \mathrm{NC@ZnO}$ to 2083 and $2098 \mathrm{~cm}^{-1}$ for $\mathrm{PdZn} /$ $\mathrm{NC@ZnO}$ and $\mathrm{Pd}_{1} / \mathrm{NC@ZnO} \mathrm{(Fig.} \mathrm{2d).} \mathrm{This} \mathrm{can} \mathrm{be} \mathrm{attributed} \mathrm{to}$ the linear combination of $\mathrm{CO}$ on $\mathrm{Pd}$ species with distinct electron deficiency in $\mathrm{Pd}-\mathrm{Zn}$ dual sites and individual $\mathrm{Pd}$ sites in comparison with $\mathrm{Pd}-\mathrm{Pd}$ sites. The varying decrease in electron density of Pd discloses the slight electron transfer from $\mathrm{Pd}$ to $\mathrm{Zn}$ atoms in $\mathrm{Pd}-\mathrm{Zn}$ dual sites and the strong electron transfer from $\mathrm{Pd}$ to the carrier in individual Pd sites ${ }^{56-59}$.

Performance evaluation for EOR. The performance for EOR is then evaluated on three catalysts with commercial $\mathrm{Pd} / \mathrm{C}$ as the reference. In 1.0 M KOH and $1.0 \mathrm{M}$ ethanol solution, cyclic voltammograms (CVs) reveal that PdZn/NC@ZnO exhibits the much higher current density than $\mathrm{Pd}_{1} / \mathrm{NC} @ Z n O, \mathrm{Pd}_{\mathrm{n}} / \mathrm{NC} @ \mathrm{ZnO}$, and $\mathrm{Pd} / \mathrm{C}$ (Fig. 3a and Supplementary Fig. 18). Unlike the negligible mass activity of $\mathrm{Pd}_{1} / \mathrm{NC@ZnO}$ and $\mathrm{Pd}_{\mathrm{n}} / \mathrm{NC@ZnO}$, the mass activity of PdZn/NC@ZnO comes up to a high level as 18.14 $\mathrm{A} \mathrm{mg}_{\mathrm{Pd}}{ }^{-1}$, which is 24 -fold to that of $\mathrm{Pd} / \mathrm{C}\left(0.76 \mathrm{~A} \mathrm{mg}_{\mathrm{Pd}}{ }^{-1}\right)$ and exceeds the performance of most Pd-based catalysts in the literature (Fig. 3b and Supplementary Table 2). It is noteworthy that the catalytic efficiency for EOR can even reach up to $77.51 \mathrm{~A} \mathrm{mg}_{\mathrm{Pd}}{ }^{-1}$ based on the surfaced Pd atoms of PdZn NPs in PdZn/NC@ZnO (Supplementary Fig. 19). The specific activity of
$\mathrm{PdZn} / \mathrm{NC} @ \mathrm{ZnO}$ is $54.60 \mathrm{~mA} \mathrm{~cm}^{-2}$, also surpassing that of $\mathrm{Pd} / \mathrm{C}$ $\left(1.48 \mathrm{~mA} \mathrm{~cm}^{-2}\right.$ ) by $\sim 37$ times (Fig. 3b). Electrochemical surface area (ECSA) for PdZn/NC@ZnO is determined to be $33.23 \mathrm{~m}^{2}$ $\mathrm{g}_{\mathrm{Pd}}{ }^{-1}$, smaller than that for $\mathrm{Pd}_{\mathrm{n}} / \mathrm{NC@ZnO}\left(36.76 \mathrm{~m}^{2} \mathrm{~g}_{\mathrm{Pd}}{ }^{-1}\right), \mathrm{Pd}_{1} /$ NC@ZnO (76.77 $\left.\mathrm{m}^{2} \mathrm{~g}_{\mathrm{Pd}}{ }^{-1}\right)$, and Pd/C (51.02 $\mathrm{m}^{2} \mathrm{~g}_{\mathrm{Pd}}{ }^{-1}$ ) (Fig. 3c and Supplementary Fig. 20 $)^{60}$. This implies the great intrinsic activity of active $\mathrm{Pd}-\mathrm{Zn}$ sites in $\mathrm{PdZn} / \mathrm{NC@ZnO}$ for EOR. Besides, the catalytic stability of PdZn/NC@ZnO is probed via chronoamperometry (CA) tests. It presents that PdZn/NC@ZnO remains larger current density all the time during the test than $\mathrm{Pd} / \mathrm{C}$ which decays rapidly (Fig. $3 \mathrm{~d}$ ), representing a superior longterm activity for EOR. Moreover, CV curves of potential cycling displays negligible loss in peak current density of PdZn/NC@ZnO before and after 2000 potential cycles (Supplementary Fig. 21). Barely no residual $\mathrm{Pd}$ and $\mathrm{Zn}$ are detected in the reaction mixture, and the content of Pd in PdZn/NC@ZnO keeps the same as $0.3 \mathrm{wt}$ $\%$ after the stability test (Supplementary Table 3 ). Corresponding characterizations of PdZn/NC@ZnO after potential cycles show no observable changes in the morphology and composition (Supplementary Figs. 22-24). These results prove the desired stability of PdZn/NC@ZnO for EOR. Obviously, the delightful activity and durability of PdZn/NC@ZnO clarifies that Pd-Zn dual sites are significantly superior to $\mathrm{Pd}-\mathrm{Pd}$ and individual $\mathrm{Pd}$ sites for EOR.

The performance of $\mathrm{PdZn} / \mathrm{NC@ZnO}$ for $\mathrm{EOR}$ is further evaluated in an actual alkaline membrane fuel cell. The polarization and power density curves in single DEFC with different electrocatalysts as anodes are shown in Supplementary Fig. 25. The opencircuit voltage of the fuel cell containing PdZn/NC@ZnO and Pd/C electrocatalysts is 0.846 and $0.843 \mathrm{~V}$, respectively. The DEFC performances of PdZn/NC@ZnO $\left(72.30 \mathrm{~mW} \mathrm{~cm}^{-2}\right)$ are better than that of $\mathrm{Pd} / \mathrm{C}\left(64.75 \mathrm{~mW} \mathrm{~cm}^{-2}\right)$. Notably, when normalizing the power density values of the DEFC with respect to the Pd loading, the electrical performance of PdZn/NC@ZnO electrode material 

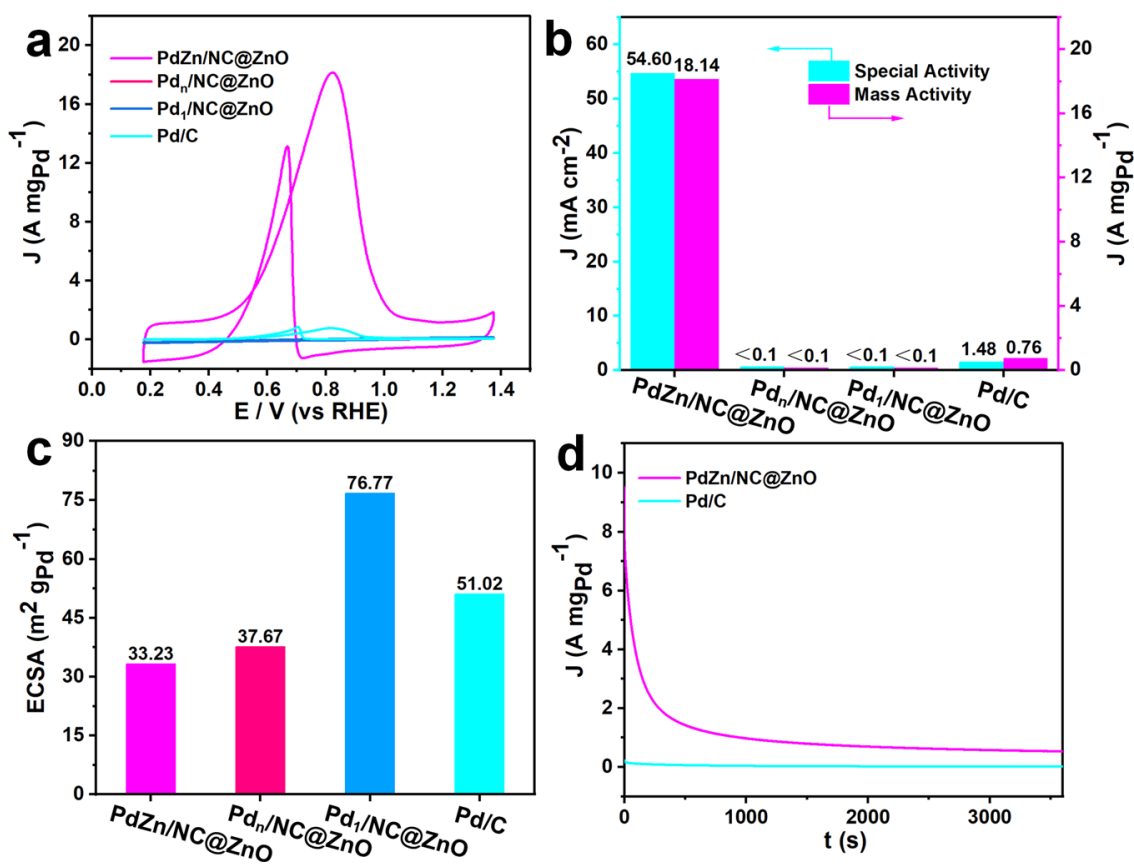

Fig. 3 Catalytic activity and durability evaluation. a CV curves of PdZn/NC@ZnO, Pdn $/ N C @ Z n O, P d_{1} / N C @ Z n O$, and commercial Pd/C, recorded in $\mathrm{N}_{2}-$ saturated $1.0 \mathrm{M} \mathrm{KOH}$ and $1.0 \mathrm{M} \mathrm{C}_{2} \mathrm{H}_{5} \mathrm{OH}$ at room temperature at scan rate of $50 \mathrm{mV} \mathrm{s}^{-1}$. b Mass and specific activities of PdZn/NC@ZnO and commercial Pd/C.c ECSA values of PdZn/NC@ZnO,Pdn/NC@ZnO,Pd $/$ NC@ZnO, and commercial Pd/C. d Chronoamperometry curves of PdZn/NC@ZnO and commercial $\mathrm{Pd} / \mathrm{C}$, recorded at their corresponding peak potentials at $-0.30 \mathrm{~V}$ vs $\mathrm{Ag} / \mathrm{AgCl}$ in aqueous solution containing $1.0 \mathrm{M} \mathrm{KOH}$ and $1.0 \mathrm{M} \mathrm{C} \mathrm{H}_{5} \mathrm{OH}$.

$\left(30.00 \mathrm{~kW} \mathrm{~g} \mathrm{gd}_{\mathrm{Pd}}{ }^{-1}\right)$ is markedly improved in comparison to the $\mathrm{Pd} / \mathrm{C}$ electrocatalyst $\left(1.295 \mathrm{~kW} \mathrm{~g} \mathrm{gd}^{-1}\right)$. Therefore, it can be concluded that the higher activity of $\mathrm{PdZn} / \mathrm{NC} @ \mathrm{ZnO}$ at lower potentials as observed in the $\mathrm{CV}$ and chronoamperometry experiments still adapts to the real operational conditions of DEFC.

Disclosing the superiority of Pd-Zn dual sites. To better understand the superiority of $\mathrm{Pd}-\mathrm{Zn}$ dual sites, we first probe into the reaction pathway of EOR over PdZn/NC@ZnO. The products in gas and liquid phase of the EOR reaction system are, respectively, analyzed by on-line GC, ion chromatography (IC), and ${ }^{1} \mathrm{H}$ NMR (Supplementary Fig. 26). It is found out that acetate is only detected product in the EOR reaction over PdZn/NC@ZnO, and no $\mathrm{CO}_{2}$ is formed. This demonstrates that the EOR proceeds the common reactive-intermediate pathway that ethanol is initially oxidized to acetaldehyde and subsequently to acetic acid or acetate in alkaline solution ${ }^{34,45,61}$.

Density functional theory (DFT) calculations are further applied to analyze the EOR procedure on three different Pdbased active sites. For the surface of intermetallic PdZn model, we compare the surface energies of (001), (100) as well as (110) surfaces, which correspond to the (002), (200), and (110) surfaces observed on PdZn/NC@ZnO by AC HAADF-STEM images (Fig. 1g). The tendency of surface energy is $(110)<(100)<(001)$ (Supplementary Table 4). Hence, the most stable (110) surface is selected as the reaction surface (Supplementary Fig. 27). Our theoretical studies suggested that for individual Pd sites the EOR process would be interrupted due to the exclusive hydrogen bond when $\mathrm{CH}_{3} \mathrm{CH}_{2} \mathrm{O}$ is formed. (Supplementary Figs. 28 and 29). As for Pd-Pd sites on Pd NPs, the ethanol adsorbs on Pd atoms and are prior to eliminate its methylene $\mathrm{C}-\mathrm{H}$ bond during the EOR process, which agrees with previous studies (Fig. 4a and Supplementary Fig. 30 $)^{62-65}$. On the contrary, for Pd-Zn dual sites on PdZn NPs, present $\mathrm{Zn}$ atoms facilitate the adsorption of ethanol on them rather than on $\mathrm{Pd}$ atoms, and let the dehydrogenation of ethanol much easier to break $\mathrm{O}-\mathrm{H}$ bond initially instead of methylene $\mathrm{C}-\mathrm{H}$ bond, adjusting the EOR procedure to a variant pathway (Fig. $4 \mathrm{~b}$ and Supplementary Fig. 31). Free energy profiles of these two different pathways are described in Fig. 4c, d and Supplementary Fig. 32. It can be observed that the reaction procedure of initial dehydrogenation of ethanol (State 2) over $\mathrm{Pd}-\mathrm{Zn}$ dual sites is easier than that over $\mathrm{Pd}-\mathrm{Pd}$ sites $\left(-37.88\right.$ vs $\left.-35.38 \mathrm{kcal} \mathrm{mol}^{-1}\right)$. After the 1 st dehydrogenation step (State 2), $\mathrm{CH}_{3} \mathrm{CHOH}$ and $\mathrm{CH}_{3} \mathrm{CH}_{2} \mathrm{O}$ are favorable on $\mathrm{Pd}$ (111) and $\mathrm{PdZn}$ (110) surface, respectively. The formed $\mathrm{CH}_{3} \mathrm{CH}_{2} \mathrm{O}$ could eliminate the possibility of parallel reactions to either $\mathrm{CH}_{3} \mathrm{CHO}$ or $\mathrm{CH}_{3} \mathrm{COH}$ in the 2nd dehydrogenation step (State3), which coexisted for the 2nd dehydrogenation step of $\mathrm{CH}_{3} \mathrm{CHOH}$ on $\mathrm{Pd}$ (111) surface. Meanwhile, the desorption processes of acetic acid on the $\mathrm{Pd}-\mathrm{Zn}$ dual sites are much easier than that on Pd-Pd sites (1.27 vs $\left.7.72 \mathrm{kcal} \mathrm{mol}^{-1}\right)$. Therefore, $\mathrm{Pd}-\mathrm{Zn}$ dual sites can enhance the interaction with ethanol and $\mathrm{OH}$ substrates and thus alter the EOR process into an energetically more favorable pathway, which contributes to the preeminent activity of $\mathrm{PdZn} / \mathrm{NC@ZnO}$ in contrast to $\mathrm{Pd}_{1} /$ NC@ZnO, Pd $/ \mathrm{NC} @ Z n O$, and commercial Pd/C.

\section{Discussion}

In conclusion, we report that creating $\mathrm{Pd}-\mathrm{Zn}$ dual sites with well exposure and homogeneity can boost the EOR to a large extent. Comparing with $\mathrm{Pd}_{\mathrm{n}} / \mathrm{NC} @ \mathrm{ZnO}$ with $\mathrm{Pd}-\mathrm{Pd}$ sites and $\mathrm{Pd}_{1} /$ $\mathrm{NC@ZnO}$ with individual Pd sites, the PdZn/NC@ZnO with $\mathrm{Pd}-\mathrm{Zn}$ dual sites displays the striking activity and good durability for EOR, even preceding commercial Pd/C significantly. DFT calculations manifest that $\mathrm{Pd}-\mathrm{Zn}$ dual sites benefit the adsorption of ethanol and $\mathrm{OH}$ with respect to $\mathrm{Pd}-\mathrm{Pd}$ sites and individual $\mathrm{Pd}$ sites, tuning the reaction pathway of EOR to proceed more smoothly with much lower energy barriers. Our study offers the clear comprehension for the role of alloyed dual sites on EOR, and may open up new opportunities to develop efficient electrocatalysts for DEFCs. 

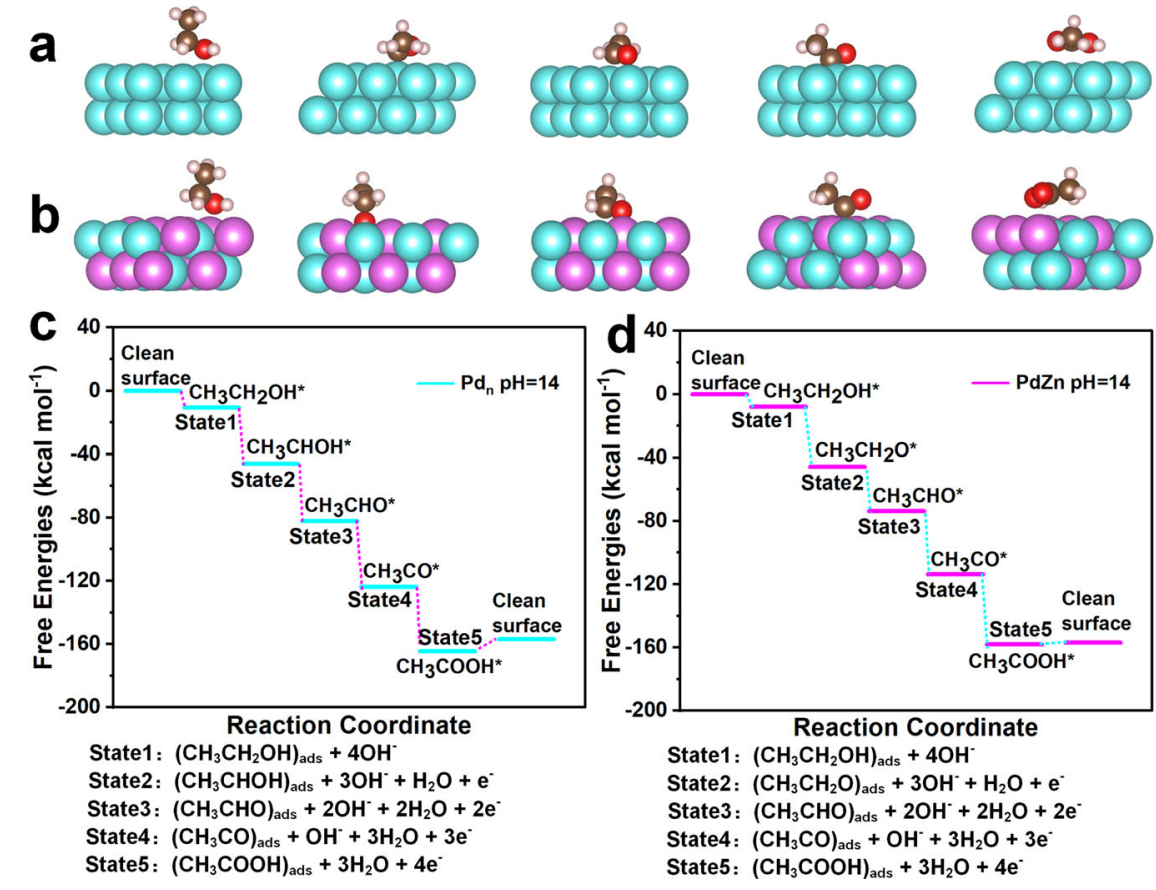

Fig. 4 DFT calculated reaction procedure of EOR on Pd-Pd sites and Pd-Zn dual sites. a DFT calculated models of Pd-Pd sites adsorbed with the reactive species from different EOR reaction states. $\mathbf{b}$ DFT calculated models of Pd-Zn dual sites adsorbed with the reactive species from different EOR reaction states. c DFT calculated free energy profiles of EOR over $\mathrm{Pd}-\mathrm{Pd}$ sites $(\mathrm{pH}=14, \mathrm{U}=0.82 \mathrm{~V}$ with respect to the RHE). $\mathbf{d}$ DFT calculated free energy profiles of EOR over $\mathrm{Pd}-\mathrm{Zn}$ dual sites $(\mathrm{pH}=14, \mathrm{U}=0.82 \mathrm{~V}$ with respect to the $\mathrm{RHE})$.

\section{Methods}

Synthesis of ZnO@PDA. ZnO nanorods were synthesized by a reported method ${ }^{53}$. Totally, $100.0 \mathrm{mg} \mathrm{ZnO}$ nanorods were dispersed in $20.0 \mathrm{~mL}$ Tris buffer solution $(10.0 \mathrm{mM}, \mathrm{pH}=8.5)$ by ultrasonication. Then dopamine hydrochloride solution (100.0 mg in $1.0 \mathrm{~mL}$ deionized water) was added to the $\mathrm{ZnO}$ suspension while stirring. The suspension was allowed to stir for $12 \mathrm{~h}$ at room temperature. The resulting products were washed by deionized water and ethanol three times and collected by centrifugation. After dried at $80^{\circ} \mathrm{C}$ in an oven, the desired ZnO@PDA was obtained.

Synthesis of Pd(OH) $/$ /ZnO@PDA. A total of $22.5 \mathrm{mg}$ of urea was added in $100 \mathrm{~mL}$ of deionized water. Then, $200.0 \mathrm{mg}$ of ZnO@PDA was added into the solution and ultrasonicated for $30 \mathrm{~min}$. Totally, $1.0 \mathrm{~mL}$ of $2.8 \mathrm{mg} \mathrm{mL}{ }^{-1} \mathrm{Na}_{2} \mathrm{PdCl}_{4}$ aqueous solution was added and stirred for $3 \mathrm{~h}$ at room temperature. The mixture was then heated up to $90^{\circ} \mathrm{C}$ for $12 \mathrm{~h}$. The products were centrifuged and washed with deionized water three times. After drying in an oven at $80^{\circ} \mathrm{C}$ overnight, $\mathrm{Pd}(\mathrm{OH})_{2} / \mathrm{ZnO} @ \mathrm{PDA}$ was obtained.

Synthesis of PdZn/NC@ZnO. The obtained Pd(OH) $/$ /ZnO@PDA was treated at $800{ }^{\circ} \mathrm{C}$ in a home-made porcelain boat with a cap under $\mathrm{H}_{2}(5 \%$ in $\mathrm{Ar})$ atmosphere for $1 \mathrm{~h}$ in a tube furnace at a ramp rate of $5^{\circ} \mathrm{C} \mathrm{min}^{-1}$ to provide PdZn/NC@ZnO.

Performance comparison of different catalysts. Electrochemical measurements were carried out with a three-electrode system on an electrochemical workstation (CHI 660, Shanghai Chenhua, China). Our experiments were performed with a saturated $\mathrm{Ag} / \mathrm{AgCl}$ electrode $(\mathrm{Ag} / \mathrm{AgCl})$ electrode as the reference electrode. It was calibrated to $E$ (RHE, reversible hydrogen electrode) from $E(\mathrm{Ag} / \mathrm{AgCl})$ by following the formula

$$
E(\mathrm{RHE})=E(\mathrm{Ag} / \mathrm{AgCl})+0.197+0.05916 \mathrm{pH}
$$

$10.0 \mathrm{mg}$ catalysts were dispersed in $950.0 \mu \mathrm{L}$ isopropanol, $950.0 \mu \mathrm{L}$ deionized water, and $100.0 \mu \mathrm{L}$ of $0.5 \mathrm{wt} \%$ Nafion solution and then followed by an intense sonication of $2 \mathrm{~h}$ to get a homogeneous $5.0 \mathrm{mg} \mathrm{mL}^{-1}$ catalyst ink. After that, $20.0 \mu \mathrm{L}$ inks (equal to $10.0 \mu \mathrm{g}$ of catalyst) were deposited onto a $5.0 \mathrm{~mm}$ diameter glassy carbon rotating disk electrode (RDE, Pine Research Instrumentation) and dried to form a uniform thin film that was further used as a working electrode. Therefore, the actual Pd loadings of PdZn/NC@ZnO, $\mathrm{Pd}_{1} / \mathrm{NC} @ Z n O, \mathrm{Pd}_{\mathrm{n}} / \mathrm{NC} @ \mathrm{ZnO}$, and commercial $\mathrm{Pd} / \mathrm{C}$ are $0.03008,0.03458,0.03983$, and $0.50000 \mu \mathrm{g}$, respectively. A carbon rod was used as the counter electrode, and a saturated $\mathrm{Ag} / \mathrm{AgCl}$ electrode was used as the reference electrode. All of the CV measurements were obtained at room temperature. The electrolyte solutions were purged with high-purity nitrogen for at least $30 \mathrm{~min}$ before use. The working electrode was initially cycled between -0.85 and $0.35 \mathrm{~V}$ at $50.0 \mathrm{mV} \mathrm{s}^{-1}$ in $1.0 \mathrm{M} \mathrm{KOH}$ for several cycles to remove the residual ligands on catalyst surface. Afterward, for the EOR measurement, the working electrodes were subject to CV scans between -0.85 and $0.65 \mathrm{~V}$ at $50 \mathrm{mV} \mathrm{s}^{-1}$ in $1.0 \mathrm{M} \mathrm{KOH}$ and $1.0 \mathrm{M}$ ethanol. The chronoamperometry measurements were conducted at $-0.30 \mathrm{~V}$ in the solution of $1.0 \mathrm{M} \mathrm{KOH}$ and $1.0 \mathrm{M}$ ethanol.

Characterizations. XRD patterns were recorded with a Rigaku D/max 2500Pc X-ray powder diffractometer with monochromatized $\mathrm{Cu}$ Ka radiation $(\lambda=1.5418 \AA$ ). TEM images were recorded by Hitachi-7700 working at $100 \mathrm{kV}$. HR-TEM, STEM, line scan analysis, and the corresponding EDX mapping were recorded by a JEOL JEM-2100F high-resolution TEM operating at $200 \mathrm{kV}$. AC HAADF-STEM images are taken on a JEOL JEMARM200F TEM/STEM with a spherical aberration corrector working at $300 \mathrm{kV}$. The lattice spacing is analyzed by Digital Micrograph software, with a calculation process explained as follows. The pixel intensities along each line parallel to the analyzed lattice fringes (several atoms length is usually included for high accuracy) are first added together, and then plotted vs. the distances along the perpendicular direction. The XPS spectrum was measured ex situ by a PHI Quantera SXM system under $3.1 \times 10^{-8} \mathrm{~Pa}$ using $\mathrm{Al}^{+}$radiation at room temperature. The binding energies were calibrated by referring $\mathrm{C}$ 1s peak to $284.8 \mathrm{eV}$. The metal content was determined by ICP-OES on Thermo Fisher IRIS Intrepid II. CO-DRIFTS characterizations are carried out on a Brucker Tenser II in situ infrared spectrometer with MCT detector using a home-made cell. The samples are pretreated with $\mathrm{Ar}$ at $25^{\circ} \mathrm{C}$ for $1 \mathrm{~h}$ $\left(20 \mathrm{~mL} \mathrm{~min}^{-1}\right)$, the background spectrum was collected. Then, $\mathrm{CO}$ gas was introduced into the sample holder for at $25^{\circ} \mathrm{C} 1 \mathrm{~h}\left(20 \mathrm{~mL} \mathrm{~min}^{-1}\right)$ and spectra were collected every $5 \mathrm{~min}$. The sample was flushing with Ar and spectra were collected every 5 min. XAS measurements were taken at BL14W1 station in Shanghai Synchrotron Radiation Facility (SSRF, operated at $3.5 \mathrm{GeV}$ with a maximum current of $250 \mathrm{~mA}$, Pd K-edge under fluorescence excitation mode). The XAS data of PdZn/ $\mathrm{NC@ZnO}, \mathrm{Pd}_{1} / \mathrm{NC} @ Z n O$, and $\mathrm{Pd}_{\mathrm{n}} / \mathrm{NC} @ \mathrm{ZnO}$ samples were collected at room temperature in fluorescence excitation mode using a Lytle detector and Ru filter. Pd film and $\mathrm{PdO}$ were used as references and measured in a transmission mode using ionization chamber. The acquired XAS data were processed according to the standard procedures using the ATHENA module implemented in the IFEFFIT software packages. The XANES spectra were gained by subtracting the post-edge background from the overall absorption and then normalizing with respect to the edge-jump step. Subsequently, the $\chi(\mathrm{k})$ data were Fourier transformed to real (R) space using a hanning windows $\left(\mathrm{dk}=1.0 \AA^{-1}\right)$ to separate the EXAFS contributions from different coordination shells. Least-squares curve parameter fitting was carried out using the ARTEMIS module of IFEFFIT software packages to obtain the quantitative structural parameters around central atoms. Gas chromatography (GC, Shimadzu, Tracera (GC-2010 Plus A, Barrier Discharge Ionization Detector (BID)-2010 Plus) 
with a GC column (Shinwa Chemical Industries, Micropacked ST) and He carrier gas (purity no less than $99.999 \%$ ). Ion Chromatography (ICS-1100, Thermo Dionex) equipped with conductivity detector, AS-DV automatic sampler, protected and analytical column: AG19 $(2 * 50 \mathrm{~mm})$ and AS19 $(4 * 250 \mathrm{~mm})$ analytical column, eluent $\mathrm{KOH}$ concentration of $20 \mathrm{mM}$, flow rate of $1 \mathrm{~mL} \mathrm{~min}^{-1}$, inhibition current of $50 \mathrm{~mA}$, column temperature of $30{ }^{\circ} \mathrm{C} .{ }^{1} \mathrm{H}$ nuclear magnetic resonance (NMR) data were recorded with a Bruker Advance III (400 MHz) spectrometer. Fuel Cell Test System (Hephas 850e).

DFT calculations. All calculations in this work were performed by $\mathrm{DMol}^{3}$ code ${ }^{66}$ The generalized gradient approximation with the Perdew-Burke-Ernzerhof functional ${ }^{67}$ was selected to deal with the exchange and correlation function. For precisely treating the long-range van der Waals interactions, we employed the empirical correction in the Grimme scheme ${ }^{68,69}$. The DFT Semi-core Pseudopots (DSPP) and double numerical plus polarization (DNP) basis set were adopted for the $\mathrm{Pd} / \mathrm{Zn}$ and $\mathrm{C} / \mathrm{H} / \mathrm{O} / \mathrm{N}$ atoms, respectively. The convergence tolerance of energy and force are $1.0 \times 10^{-5} \mathrm{Ha}$, and $2.0 \times 10^{-3} \mathrm{Ha} / \AA$ during the fully geometry optimization. The vacuum space along $z$ direction is set to be $15 \mathrm{~A}$ to avoid interaction between the two neighboring images. A Monkhorst-pack mesh of $2 \times 2 \times 1,2 \times 1 \times 1$, and $1 \times 1 \times 1 \mathrm{k}$-points was used in sampling the integrals over the Brillouin zone, for Pd-Pd sites, Pd-Zn dual sites, and individual Pd sites related models, respectively ${ }^{70}$. Calculated lattice constants for PdZn are 3.003 and $3.232 \AA$, which are in good agreement with them in Materialsprojects $(2.895 \text { and } 3.342 \AA)^{71}$. Slab models of $p$ $(3 \times 3) \mathrm{Pd}(111)$ and $p(2 \times 3) \mathrm{PdZn}(110)$ were selected as the substrates for ethanol electro-oxidation reaction. $\mathrm{Pd}-\mathrm{N}_{4}$ (pyridine- $\left.\mathrm{N}_{4}\right)$ embedded in $p(6 \times 6)$ graphene model was selected as the single-atom catalyst substrate. The adsorption energies were calculated according to the formula,

$$
E a d s=E(\text { adsorbate } / \text { sub })-E(\text { adsorbate })-E(\text { sub })
$$

where $E$ (adsorbate/sub), $E$ (adsorbate), and $E$ (sub) represent the total energy of substrate with adsorbed species, the adsorbate species, and the clean substrate. The change in free energy for all the elementary steps is calculated based on the computational hydrogen electrode method developed by Norskov and his co-workers ${ }^{72}$. the reaction free energy $\Delta G$ is defined as the difference between free energies of the final and initial states and is given by the formula:

$$
\Delta G=\Delta E+\Delta Z P E-T \Delta S+\Delta G_{U}+\Delta G_{p H}
$$

where $\Delta E$ is the DFT calculated reaction energy of reactant and product molecules adsorbed on substeates; $\triangle Z P E$ and $\triangle S$ are the change in zero-point energies and entropy due to the reaction. The bias effect on the free energy of each initial, intermediate and final state involving an electron in the electrode is taken into accounts by shifting the energy of the state by

$$
\Delta G_{U}=-n e U
$$

where $U$ is the electrode applied potential. $\Delta G_{\mathrm{pH}}$ is the correction of the $\mathrm{H}^{+}$ free energy at a $\mathrm{pH}$ different from 0 :

$$
\Delta G_{p H}=-k_{B} T \ln \left[H^{+}\right]=p H \times k_{B} T \ln 10
$$

where $k_{\mathrm{B}}$ is the Boltzmann constant and $T$ is the temperature. The equilibrium potential at $\mathrm{pH}=14$ was determined to be $0.402 \mathrm{~V}$ versus normal hydrogen electrode (NHE) according to the Nernst equation.

The considered EOR occurring in an alkaline electrolyte $(\mathrm{pH}=14)$ are shown in the following steps ${ }^{44,65,73}$.

$$
\begin{aligned}
\mathrm{CH}_{3} \mathrm{CH}_{2} \mathrm{OH}^{*}+\mathrm{OH}^{-} & \rightarrow \mathrm{CH}_{3} \mathrm{CH}_{2} \mathrm{O}^{*}+\mathrm{H}_{2} \mathrm{O}+\mathrm{e}^{-} \\
\mathrm{CH}_{3} \mathrm{CH}_{2} \mathrm{OH}^{*}+\mathrm{OH}^{-} & \rightarrow \mathrm{CH}_{3} \mathrm{CHOH}^{*}+\mathrm{H}_{2} \mathrm{O}+\mathrm{e}^{-} \\
\mathrm{CH}_{3} \mathrm{CH}_{2} \mathrm{OH}^{*}+\mathrm{OH}^{-} & \rightarrow \mathrm{CH}_{3} \mathrm{CHOH}^{*}+\mathrm{H}_{2} \mathrm{O}+\mathrm{e}^{-} \\
\mathrm{CH}_{3} \mathrm{CHOH}^{*}+\mathrm{OH}^{-} & \rightarrow \mathrm{CH}_{3} \mathrm{CHO}^{*}+\mathrm{H}_{2} \mathrm{O}+\mathrm{e}^{-} \\
\mathrm{CH}_{3} \mathrm{CHOH}^{*}+\mathrm{OH}^{-} & \rightarrow \mathrm{CH}_{3} \mathrm{CHO}^{*}+\mathrm{H}_{2} \mathrm{O}+\mathrm{e}^{-} \\
\mathrm{CH}_{3} \mathrm{CHOH}^{*}+\mathrm{OH}^{-} & \rightarrow \mathrm{CH}_{3} \mathrm{CHO}^{*}+\mathrm{H}_{2} \mathrm{O}+\mathrm{e}^{-} \\
\mathrm{CH}_{3} \mathrm{CHOH}^{*}+\mathrm{OH}^{-} & \rightarrow \mathrm{CH}_{3} \mathrm{CHO}^{*}+\mathrm{H}_{2} \mathrm{O}+\mathrm{e}^{-} \\
\mathrm{CH}_{3} \mathrm{CO}^{*}+\mathrm{OH}^{-} & \rightarrow \mathrm{CH}_{3} \mathrm{COOH}^{*}+\mathrm{e}^{-}
\end{aligned}
$$

\section{Data availability}

The data supporting this study are available from the authors upon reasonable request.

Received: 1 April 2021; Accepted: 19 August 2021;

Published online: 06 September 2021

\section{References}

1. Zhang, J. et al. Cyclic penta-twinned rhodium nanobranches as superior catalysts for ethanol electro-oxidation. J. Am. Chem. Soc. 140, 11232-11240 (2018).

2. Wang, H. \& Liu, Z. Comprehensive mechanism and structure-sensitivity of ethanol oxidation on platinum: new transition-state searching method for resolving the complex reaction network. J. Am. Chem. Soc. 130, 10996-11004 (2008).

3. Bianchini, C. \& Shen, P. Palladium-based electrocatalysts for alcohol oxidation in half cells and in direct alcohol fuel cells. Chem. Rev. 109, 4183-4206 (2009).

4. Zhou, Z. et al. High-index faceted platinum nanocrystals supported on carbon black as highly efficient catalysts for ethanol electrooxidation. Angew. Chem. Int. Ed. 49, 411-414 (2010).

5. Zhou, M., Li, C. \& Fang, J. Noble-metal based random alloy and intermetallic nanocrystals: syntheses and applications. Chem. Rev. 121, 736-795 (2021).

6. Li, S. et al. Engineering three-dimensional nitrogen-doped carbon black embedding nitrogen-doped graphene anchoring ultrafine surface-clean Pd nanoparticles as efficient ethanol oxidation electrocatalyst. Appl. Catal. B. 280, 119464 (2021).

7. Yang, X. et al. A phosphorus-doped Ag@Pd catalyst for enhanced C-C bond cleavage during ethanol electrooxidation. Small 16, e2004727 (2020).

8. Zhu, Y., Bu, L., Shao, Q. \& Huang, X. Structurally ordered $\mathrm{Pt}_{3} \mathrm{Sn}$ nanofibers with highlighted antipoisoning property as efficient ethanol oxidation electrocatalysts. ACS Catal. 10, 3455-3461 (2020).

9. Xu, H., Shang, H., Wang, C. \& Du, Y. Ultrafine Pt-based nanowires for advanced catalysis. Adv. Funct. Mater. 30, 2000793 (2020).

10. Lyu, F., Cao, M., Mahsud, A. \& Zhang, Q. Interfacial engineering of noble metals for electrocatalytic methanol and ethanol oxidation. J. Mater. Chem. A 8, 15445-15457 (2020).

11. Li, S. et al. Flexible solid-state direct ethanol fuel cell catalyzed by nanoporous high-entropy Al-Pd-Ni-Cu-Mo anode and spinel (AlMnCo) ${ }_{3} \mathrm{O}_{4}$ cathode. $A d v$. Funct. Mater. 31, 2007129 (2020).

12. Basumatary, P., Konwar, D. \& Yoon, Y. Conductivity-tailored PtNi/MoS 3 3D nanoflower catalyst via Sc doping as a hybrid anode for a variety of hydrocarbon fuels in proton exchange membrane fuel cells. Appl. Catal. B. 267, 118724 (2020)

13. Bambagioni, V. et al. Ethanol oxidation on electrocatalysts obtained by spontaneous deposition of palladium onto nickel-zinc materials. ChemSusChem 2, 99-112 (2009).

14. Marchionni, A. et al. Electrooxidation of ethylene glycol and glycerol on Pd-(Ni$\mathrm{Zn}$ )/C anodes in direct alcohol fuel cells. ChemSusChem 6, 518-528 (2013).

15. Bianchini, C. et al. Selective oxidation of ethanol to acetic acid in highly efficient polymer electrolyte membrane-direct ethanol fuel cells. Electrochem. Commun. 11, 1077-1080 (2009).

16. An, L. \& Zhao, T. An alkaline direct ethanol fuel cell with a cation exchange membrane. Energy Environ. Sci. 4, 2213-2217 (2011).

17. Monyoncho, E., Woo, T. \& Baranova, A. Ethanol electrooxidation reaction in alkaline media for direct ethanol fuel cells. Electrochemistry 13, 1-57 (2018).

18. Zhang, W. et al. Ultrathin PtNiM $(\mathrm{M}=\mathrm{Rh}$, Os, and Ir) nanowires as efficient fuel oxidation electrocatalytic materials. Adv. Mater. 31, e1805833 (2019).

19. Fan, X. et al. Promoting the electrocatalytic performance of noble metal aerogels by ligand-directed modulation. Angew. Chem. Int. Ed. 59, 5706-5711 (2020)

20. Du, R. et al. Freeze-thaw-promoted fabrication of clean and hierarchically structured noble-metal aerogels for electrocatalysis and photoelectrocatalysis. Angew. Chem. Int. Ed. 59, 8293-8300 (2020).

21. Du, R. et al. Unveiling reductant chemistry in fabricating noble metal aerogels for superior oxygen evolution and ethanol oxidation. Nat. Commun. 11, 1590-1600 (2020)

22. Li, M. et al. Single-atom tailoring of platinum nanocatalysts for highperformance multifunctional electrocatalysis. Nat. Catal. 2, 495-503 (2019).

23. $\mathrm{Li}$, J. et al. Ternary CoPtAu nanoparticles as a general catalyst for highly efficient electro-oxidation of liquid fuels. Angew. Chem. Int. Ed. 58, 11527-11533 (2019)

24. Dutta, A., Adhikary, R., Broekmann, P. \& Datta, J. Intelligent catalytic support by $\mathrm{Ni} / \mathrm{NiO} / \mathrm{Ni}(\mathrm{OH})_{2}$ in low level of $\mathrm{Pd} / \mathrm{Pt}$ boosting the performance of alkaline DEFC. Appl. Catal. B. 257, 117847 (2019).

25. Liang, Z. et al. Direct 12-electron oxidation of ethanol on a ternary Au(core)PtIr(shell) electrocatalyst. J. Am. Chem. Soc. 141, 9629-9636 (2019).

26. Xiong, Y. et al. Cobalt single atom site catalysts with ultrahigh metal loading for enhanced aerobic oxidation of ethylbenzene. Nano Res. 13, 1-6 (2021).

27. Zeng, L. \& Xue, C. Single metal atom decorated photocatalysts: progress and challenges. Nano Res. 13, 1-11 (2020).

28. Wu, W. et al. Single copper sites dispersed on hierarchically porous carbon for improving oxygen reduction reaction towards zinc-air battery. Nano Res. 14, 998-1003 (2021).

29. Chen, Y. et al. Atomic-level modulation of electronic density at cobalt singleatom sites derived from metal-organic frameworks: enhanced oxygen reduction performance. Angew. Chem. Int. Ed. 60, 3212-3221 (2021). 
30. Yang, J., Li, W., Wang, D. \& Li, Y. Single-atom materials: small structures determine macroproperties. Small Struct. 2, 2000051 (2021).

31. Cao, Y. et al. Adsorption site regulation to guide atomic design of Ni-Ga catalysts for acetylene semi-hydrogenation. Angew. Chem. Int. Ed. 132, 11744-11749 (2020).

32. Yun, Q. et al. Synthesis of PdM $(M=\mathrm{Zn}, \mathrm{Cd}, \mathrm{ZnCd})$ nanosheets with an unconventional face-centered tetragonal phase as highly efficient electrocatalysts for ethanol oxidation. ACS Nano. 13, 14329-14336 (2019).

33. Yin, P. et al. Synthesis of palladium-based crystalline@amorphous core-shell nanoplates for highly efficient ethanol oxidation. Adv. Mater. 32, e2000482 (2020).

34. Yu, X. et al. Phosphorous incorporation in $\mathrm{Pd}_{2} \mathrm{Sn}$ alloys for electrocatalytic ethanol oxidation. Nano Energy 77, 105116 (2020).

35. Tiwari, J. et al. Remarkably enhanced catalytic activity by the synergistic effect of palladium single atoms and palladium-cobalt phosphide nanoparticles. Nano Energy 78, 105116 (2020).

36. Jiang, K. et al. Ordered PdCu-based nanoparticles as bifunctional oxygenreduction and ethanol-oxidation electrocatalysts. Angew. Chem. Int. Ed. 55, 9030-9035 (2016).

37. Sarkar, S. et al. Ordered $\mathrm{Pd}_{2} \mathrm{Ge}$ intermetallic nanoparticles as highly efficient and robust catalyst for ethanol oxidation. Chem. Mater. 27, 7459-7467 (2015).

38. Sneed, B. et al. Nanoscale-phase-separated Pd-Rh boxes synthesized via metal migration: an archetype for studying lattice strain and composition effects in electrocatalysis. J. Am. Chem. Soc. 135, 14691-14700 (2013).

39. $\mathrm{Yu}, \mathrm{X}$. et al. Stability of $\mathrm{Pd}_{3} \mathrm{~Pb}$ nanocubes during electrocatalytic ethanol oxidation. Chem. Mater. 32, 2044-2052 (2020).

40. Luo, L. et al. Composition-graded Cu-Pd nanospheres with $\mathrm{Ir}$-doped surfaces on $\mathrm{N}$-doped porous graphene for highly efficient ethanol electro-oxidation in alkaline media. ACS Catal. 10, 1171-1184 (2020).

41. Gao, F., Zhang, Y., Ren, F., Shiraishi, Y. \& Du, Y. Universal surfactant-free strategy for self-standing 3D tremella-like $\mathrm{Pd}-\mathrm{M}(\mathrm{M}=\mathrm{Ag}, \mathrm{Pb}$, and $\mathrm{Au})$ nanosheets for superior alcohols electrocatalysis. Adv. Funct. Mater. 30, 2000255 (2020).

42. Lopez, A. et al. Facile removal of stabilizer-ligands from supported gold nanoparticles. Nat. Chem. 3, 551-556 (2011).

43. Ge, J. et al. Ultrathin palladium nanomesh for electrocatalysis. Angew. Chem. Int. Ed. 57, 3435-3438 (2018).

44. Chen, L. et al. Improved ethanol electrooxidation performance by shortening Pd$\mathrm{Ni}$ active site distance in Pd-Ni-P nanocatalysts. Nat. Commun. 8, 14136 (2017).

45. Wu, D. et al. Platinum-group-metal high-entropy-alloy nanoparticles. J. Am. Chem. Soc. 142, 13833-13838 (2020).

46. Du, W. et al. Platinum-tin oxide core-shell catalysts for efficient electrooxidation of ethanol. J. Am. Chem. Soc. 136, 10862-10865 (2014).

47. Wang, W. et al. Edge enrichment of ultrathin 2D PdPtCu trimetallic nanostructures effectuates top-ranked ethanol electrooxidation. Nano Lett. 20, 5458-5464 (2020).

48. Wang, Y., Zou, S. \& Cai, W. Recent advances on electro-oxidation of ethanol on Pt- and Pd-based catalysts: from reaction mechanisms to catalytic materials. Catalysts 5, 1507-1534 (2015).

49. Gao, Q. et al. Monodisperse PdSn/SnOx core/shell nanoparticles with superior electrocatalytic ethanol oxidation performance. J. Mater. Chem. A. 8, 20931-20938 (2020).

50. Hong, W., Wang, J. \& Wang, E. Facile synthesis of highly active PdAu nanowire networks as self-supported electrocatalyst for ethanol electrooxidation. ACS Appl. Mater. Inter. 6, 9481-9487 (2014).

51. Qi, Z. et al. Sub-4 nm PtZn intermetallic nanoparticles for enhanced mass and specific activities in catalytic electrooxidation reaction. J. Am. Chem. Soc. 139, 4762-4768 (2017).

52. Han, A. et al. Isolating contiguous Pt atoms and forming Pt-Zn intermetallic nanoparticles to regulate selectivity in 4-nitrophenylacetylene hydrogenation. Nat. Commun. 10, 3787 (2019).

53. Cheng, B. \& Samulski, E. Hydrothermal synthesis of one-dimensional $\mathrm{ZnO}$ nanostructures with different aspect ratios. Chem. Commun. 8, 986-987 (2004).

54. Zhou, H. et al. PdZn intermetallic nanostructure with Pd-Zn-Pd ensembles for highly active and chemoselective semi-hydrogenation of acetylene. ACS Catal. 6, 1054-1061 (2016).

55. Castillejos-López, E., Agostini, G., Di Michel, M., Iglesias-Juez, A. \& BachillerBaeza, B. Synergy of contact between $\mathrm{ZnO}$ surface planes and $\mathrm{PdZn}$ nanostructures: morphology and chemical property effects in the intermetallic sites for selective 1,3-butadiene hydrogenation. ACS Catal. 7, 796-811 (2016).

56. Zhang, Z. et al. Pd single-atom monolithic catalyst: functional 3D structure and unique chemical selectivity in hydrogenation reaction. Sci. China Mater. 13, 1-11 (2021).

57. Bahruji, $\mathrm{H}$. et al. Solvent free synthesis of $\mathrm{PdZn} / \mathrm{TiO}_{2}$ catalysts for the hydrogenation of $\mathrm{CO}_{2}$ to methanol. Top. Catal. 61, 144-153 (2018).

58. Eblagon, K., Concepción, P., Silva, H. \& Mendes, A. Ultraselective low temperature steam reforming of methanol over $\mathrm{PdZn} / \mathrm{ZnO}$ catalysts-
Influence of induced support defects on catalytic performance. Appl. Catal. B. 154, 316-328 (2014).

59. Rameshan, C. et al. Subsurface-controlled $\mathrm{CO}_{2}$ selectivity of PdZn nearsurface alloys in $\mathrm{H}_{2}$ generation by methanol steam reforming. Angew. Chem. Int. Ed. 49, 3224-3227 (2010).

60. Łukaszewski, M. Electrochemical methods of real surface area determination of noble metal electrodes-an overview. Int. J. Electrochem. Sci. 11, 4442-4469 (2016).

61. Bambagioni, V. et al. Ethanol oxidation on electrocatalysts obtained by spontaneous deposition of palladium onto nickel-zinc materials. ChemSusChem 2, 99-112 (2009).

62. Monyoncho, E. et al. Ethanol electro-oxidation on palladium revisited using polarization modulation infrared reflection absorption spectroscopy (PMIRRAS) and density functional theory (DFT): Why is it difficult to break the C-C bond? ACS Catal. 6, 4894-4906 (2016)

63. Miao, B., Wu, Z., Zhang, M., Chen, Y. \& Wang, L. Role of Ni in bimetallic PdNi catalysts for ethanol oxidation reaction. J. Phys. Chem. C. 122, 22448-22459 (2018).

64. Wang, E., Xu, J. \& Zhao, T. Density functional theory studies of the structure sensitivity of ethanol oxidation on palladium surfaces. J. Phys. Chem. C. 114, 10489-10497 (2010).

65. Hibbitts, D. \& Neurock, M. Influence of oxygen and $\mathrm{pH}$ on the selective oxidation of ethanol on Pd catalysts. J. Catal. 299, 261-271 (2013).

66. Delley, B. From molecules to solids with the $\mathrm{DMol}^{3}$ approach. J. Chem. Phys. 113, 7756-7764 (2000).

67. John, P., Perdew, K. \& Matthias, E. Generalized gradient approximation made simple. Phys. Rev. Lett. 77, 4 (1996).

68. Grimme, S. Semiempirical GGA-type density functional constructed with a long-range dispersion correction. J. Comput. Chem. 27, 1787-1799 (2006).

69. Mcnellis, E., Meyer, J. \& Reuter, K. Azobenzene at coinage metal surfaces: role of dispersive van der Waals interactions. Phys. Rev. B. 80, 10 (2009).

70. Monkhorst, H. \& Pack, J. Special points for Brillouin-zone integrations. Phys Rev. B. 13, 5188-5192 (1976)

71. Jain, A. et al. The materials project: a materials genome approach to accelerating materials innovation. APL Mater. 1, 11 (2013).

72. Nørskov, J., Logadottir, A. \& Lindqvist, L. Origin of the overpotential for oxygen reduction at a fuel-cell cathode. J. Phys. Chem. B. 108, 7 (2004).

73. Wei, L. et al. Concave cubic Pt-Sm alloy nanocrystals with high-index facets and enhanced electrocatalytic ethanol oxidation. J. Catal. 2, 7204-7210 (2019)

\section{Acknowledgements}

This work was supported by the National Key R\&D Program of China (2018YFA0702003), the National Natural Science Foundation of China (21890383, 21871159, and 52002249), Science and Technology Key Project of Guangdong Province of China (2020B010188002), the Guangdong Basic and Applied Basic Research Foundation (2019A1515110025), the National Postdoctoral Program for Innovative Talents (BX20190167), the Shuimu Tsinghua Scholar Program, the China Postdoctoral Science Foundation (2020M670283). We thank the BL14W1 station of Shanghai Synchrotron Radiation Facility (SSRF) for XAFS measurements.

\section{Author contributions}

Y.Q. performed the experiments, collected and analyzed the data, and wrote the paper W.S. conducted the density functional theory calculation and analysis. Z.Z. helped with XANES and EXAFS spectrometry analyses. L.G. assisted in the AC HAADF-STEM characterization. J.J., J.S., Q.C., G.M., Q.X., Y.Z., H.T. and A.H. helped with data analysis and discussions. J.Z., D.W. and Y.L. conceived the experiments, planned synthesis, analyzed results, and wrote the paper.

\section{Competing interests}

The authors declare no competing interests.

\section{Additional information}

Supplementary information The online version contains supplementary material available at https://doi.org/10.1038/s41467-021-25600-9.

Correspondence and requests for materials should be addressed to J.Z., W.S. or D.W.

Peer review information Nature Communications thanks Francesco Vizza and the other, anonymous, reviewer(s) for their contribution to the peer review of this work. Peer reviewer reports are available.

Reprints and permission information is available at http://www.nature.com/reprints

Publisher's note Springer Nature remains neutral with regard to jurisdictional claims in published maps and institutional affiliations. 
(c) (i) Open Access This article is licensed under a Creative Commons Attribution 4.0 International License, which permits use, sharing, adaptation, distribution and reproduction in any medium or format, as long as you give appropriate credit to the original author(s) and the source, provide a link to the Creative Commons license, and indicate if changes were made. The images or other third party material in this article are included in the article's Creative Commons license, unless indicated otherwise in a credit line to the material. If material is not included in the article's Creative Commons license and your intended use is not permitted by statutory regulation or exceeds the permitted use, you will need to obtain permission directly from the copyright holder. To view a copy of this license, visit http://creativecommons.org/ licenses/by/4.0/.

(c) The Author(s) 2021, corrected publication 2022 